\title{
Agouti yellow mutation increases adrenal response to ACTH in mice
}

\author{
Nadezhda M Bazhan, Antonina Y Shevchenko, Nelli R Karkaeva, Tatyana V Yakovleva and Elena N Makarova \\ Institute of Cytology and Genetics, Russian Academy of Sciences, Pr. Lavrentjeva 10, Novosibirsk 630090, Russia \\ (Correspondence should be addressed to N M Bazhan; Email: bazhan@bionet.nsc.ru)
}

\begin{abstract}
Objective: Agouti protein (AP) and agouti-related protein with a similar sequence and action are endogenous antagonists of melanocortin receptors, implicated in the control of the hypothalamo-pituitary-adrenal (HPA) axis. Dominant mutation of the agouti gene (agouti yellow $\left(A^{y}\right)$ ) in heterozygous $A^{y} / a$ mice leads to ectopic overexpression of AP and produces an obese phenotype. The existing data on the HPA function in $A^{y} / a$-mice are equivocal; therefore, the present study aimed to assess HPA function in 3-month-old male $C 57 \mathrm{Bl} / 6 \mathrm{~J}$ mice of two agouti genotypes: $A \% / a$ (ectopic AP overexpression) and $a / a$ (absence of AP).

Design and methods: In order to evaluate the HPA function, activating (15-min restriction, ACTHinduced corticosterone production in vitro) and inhibiting (i.p. injection of dexamethasone, $0.02 \mu \mathrm{g} / \mathrm{g}$ body weight) stimuli were employed. To estimate the effect of obesity on some HPA functions, $A^{y} / a$ males were subdivided into obese and non-obese groups.

Results: Basal plasma concentrations of ACTH and corticosterone; basal corticosterone production in vitro; and feedback inhibition of resting corticosterone levels by dexamethasone were similar in $A^{y} / a$ and $a / a$-mice. Restraint-induced plasma corticosterone was greater in obese and non-obese $A y / a$-mice than in a/a-mice, whereas restraint-induced plasma ACTH levels were similar. Adrenal cell responses to ACTH $\left(10^{-13}-10^{-10} \mathrm{M}\right)$ were higher in obese and non-obese $A^{y} / a$-mice than in a/a-mice. Dexamethasone, injected $3 \mathrm{~h}$ prior to stress, inhibited stress-induced corticosterone levels by a significantly greater amount in $A^{y} / a$-mice than in $a / a$-mice.

Conclusions: AP may have both stimulating and inhibiting influences on the HPA axis. AP overproduction increased the response of the HPA to short-restraint stress due to increased adrenal responsiveness to ACTH; this result was not effected by obesity development.
\end{abstract}

European Journal of Endocrinology 151 265-270

\section{Introduction}

The melanocortin system is implicated in the control of the hypothalamo-pituitary-adrenal (HPA) axis. Adrenocorticotropin (ACTH) and $\alpha$-melanocyte-stimulating hormone $(\alpha-\mathrm{MSH})$ are endogenous agonists of melanocortin receptors (MC-Rs). In addition to MC2$\mathrm{R}$ (a predominant ACTH receptor), MC3-R, MC4-R and MC5-R have been found in the adrenal (1-3). MC3-R and MC4-R have been found in rat and human hypothalamus (4). Agouti protein (AP) and agouti-related protein (AgRP), with a similar sequence and action (5), are endogenous antagonists of melanocortin receptors $(6,7)$. AP is usually expressed only in the skin, regulating coat color in mice (8). Ectopic overexpression of AP due to autosomal dominant mutation agouti yellow in mice $\left(A^{y} / a\right.$-mice $)$ results in a phenotype of yellow coat color, type II diabetes, adult onset obesity, increased incidence of tumors and increased somatic growth (9). The complexity of the phenotype is obviously due to $\mathrm{AP}$ antagonizing the MC-R subtypes.

The fact that AP is an antagonist of MC-Rs, which localize in the HPA axis, suggests that AP should effect both central and peripheral links of the HPA axis in $A^{y}$-mice. Nevertheless basal and stress-activated levels of corticosterone in the lethal yellow $\left(A^{y / a}\right)$ obese mice have been previously reported to be within normal limits $(9,10)$. This stands in contrast with data previously obtained in our laboratory in $A^{y}$-mice ( 11 , 12) and studies of transgenic mice with ectopic expression of AP (13) which demonstrated increased corticosterone responses to restraint stress.

It was shown that AP and its analog AgRP may exert both activating and inhibiting actions on adrenal and hypothalamus. Adrenal AgRP, via the MC3-R or MC4-R, blocks $\alpha$-MSH-induced corticosterone secretion in rats (3). Human recombinant agouti protein was shown to be a potent inhibitor of MC2-R signaling in OS3 cells (adrenal cortical lineage) (7). On the other 
hand, Dhillo et al. (14) recently demonstrated that i.c.v. administration of $\alpha$-MSH or AgRP increased plasma ACTH in male rats. These results suggest that AgRP may activate the HPA axis.

We hypothesize that the agouti yellow mutation, resulting in ectopic overexpression of AP, has effects on HPA function. These effects might be both stimulating and inhibiting, thus compensating each other to some extent. To test this hypothesis we examined the following parameters in lethal yellow $\left(A^{y} / a\right)$ mice: (1) HPA response to restraint stress in vivo; (2) adrenal gland response to ACTH stimulation in vitro; (3) HPA response to inhibition (dexamethasone treatment) in vivo. To take into account possible obesity effects on the HPA axis special experiments were conducted, in which we formed groups of obese and non-obese $A^{y}$-mice due to high weight individual variability among them.

\section{Materials and methods}

Materials were obtained from the following sources: corticosterone, ACTH (1-39), EDTA, heparin, collagenase type 1A, BSA from Sigma; dexamethasone from Serva; $\left[1,2,6,7,-{ }^{3} \mathrm{H}\right]$ corticosterone from Amersham; ACTH-kit from CIS Bio International ORIS Group, France.

\section{Animals}

The study was undertaken on 3-month-old male $C 57 \mathrm{Bl} / 6 \mathrm{~J}$ mice of two agouti genotypes: $A^{y} / a$ with ectopic AP overexpression $(8,9)$ and $a / a$ with absence of AP (15). Mice of $a / a$ and $A^{y} / a$ genotypes were sibs obtained from reciprocal crosses $A^{y} / a \times a / a$ and $a / a \times A^{y} / a$. Animals were bred at the vivarium of the Institute of Cytology and Genetics (Siberian Division, Russian Academy of Sciences, Novosibirsk). Animals were housed in groups of five per cage under natural light conditions, at an ambient temperature $21^{\circ} \mathrm{C}$ and with free access to water and food. Mice were caged separately 4 days before the experiments. Because of circadian rhythms, all experiments started between 0900 and $1000 \mathrm{~h}$. All studies were carried out to the highest standards of humane animal care.

The $A^{y / a-m i c e}$ used in the experiments weighed more than the a/a-mice (average body weight: $A^{y} / a$ males, $-27.2 \pm 0.1 \mathrm{~g}(n=45)$; a/a males, $-23.6 \pm 0.3$ g $(n=45) ; P<0.001$, t-test). Hence, obesity has already developed at 3 months of age in $A^{y / a}$ males. In order to assess the effect of melanocortin obesity on the adrenal response to restraint and to ACTH (in vitro), 3-month-old males of $A^{y} / a$ genotype were subdivided into two groups: obese with body weight $36.7 \pm 1.0 \mathrm{~g} \quad(n=22)$, and non-obese with body weight $26.0 \pm 0.8 \mathrm{~g}(n=22)$. For comparison their $a / a$ sibs with body weight $24.4 \pm 0.4 \mathrm{~g}(n=22)$ were also studied.

\section{Blood samples}

Blood samples were obtained by tail nick $(50 \mu \mathrm{l})$ or by decapitation. After tail nick, blood was drawn into prechilled plastic tubes containing heparin $(1000 \mathrm{U} / \mathrm{ml})$. After decapitation trunk blood was collected into prechilled plastic tubes - containing heparin for corticosterone analysis and EDTA $(1-2 \mathrm{mM})$ for ACTH analysis. Plasma was separated by centrifugation in a refrigerated centrifuge (15 min at 3000 r.p.m. at $4^{\circ} \mathrm{C}$ ) and immediately frozen at $-20^{\circ} \mathrm{C}$ until assayed.

\section{Restraint stress}

Mice of each genotype were subdivided into control and restraint groups (8-9 mice/group). Restraint mice were placed in restraint tubes (diameter, $2 \mathrm{~cm}$ ) and killed immediately after 15-min restraint. Control mice were killed within 2 min of disturbance.

In experiments studying the effect of obesity on the HPA response to restraint stress, non-obese and obese $A^{y} / a$ males and $a / a$ males ( 7 mice/group) were exposed to 15 -min restraint stress. Blood was collected, by tail nick, before (control) and immediately after restraint stress (restraint).

\section{Adrenal response to $A C T H$ in vitro}

Mice were killed and adrenal glands were rapidly removed, cleared and diced into small pieces. Adrenals from five mice of the same genotype were pulled and incubated in $1.5 \mathrm{ml}$ Krebs-Ringer bicarbonate-glucose buffer (KRBB, pH 7.4, 4\% BSA, 4\% collagenase) for $60 \mathrm{~min}$ at $37^{\circ} \mathrm{C}$ in an atmosphere of $95 \% \mathrm{O}_{2}$ and $5 \% \mathrm{CO}_{2}$. Adrenal cells were dispersed by gentle homogenization (repeated pipetting) and filtered through nylon gauze. Suspensions were centrifuged $\left(4^{\circ} \mathrm{C}\right.$, $10 \mathrm{~min}$ at 300 r.p.m. then $10 \mathrm{~min}$ at 800 r.p.m.) and washed three times with $2.5 \mathrm{ml}$ cold KRBB $(0.5 \%$ BSA). After the final centrifugation, the cells were resuspended in $2.0 \mathrm{ml}$ KRBB $(0.5 \%$ BSA) and counted with trypan blue in a hemocytometer chamber. Cells were then dissolved with $\mathrm{KRBB}(0.5 \% \mathrm{BSA})$ to a final concentration of $4 \times 10^{5}$ cells $/ \mathrm{ml}$. Aliquots $(200 \mu \mathrm{l})$ were incubated for $2 \mathrm{~h}$ in an atmosphere of $95 \% \mathrm{O}_{2}$ and $5 \% \mathrm{CO}_{2}$ in the presence or absence of different doses of ACTH $\left(10^{-13}, 10^{-12}, 10^{-11}\right.$ and $\left.10^{-10} \mathrm{M}\right)$. After incubation, cells were sedimented by brief centrifugation ( $5 \mathrm{~min}$ at 2000 r.p.m.). The cell-free medum was decanted and stored at $-20^{\circ} \mathrm{C}$ until corticosterone assay. The experiment was performed in triplicate.

\section{Sensitivity of the HPA axis to dexamethasone}

Males of each genotype were divided into two groups (12-13 mice/group). Animals in the first group were injected (i.p.) with saline; animals in the second 
group were injected with dexamethasone $(0.02 \mu \mathrm{g} / \mathrm{g}$ body weight). Three hours after injection, at $1200 \mathrm{~h}$, all animals were restrained for $15 \mathrm{~min}$. Blood was collected, by tail nick, before and immediately after restraint stress. The experimental design therefore resulted in four groups of data: (1) saline, before restriction; (2) saline, after restriction; (3) dexamethasone, before restriction; (4) dexamethasone, after restriction.

\section{Hormone assay}

Corticosterone was measured by the method of competitive protein binding (16) using serum of female mice with inner transcortin, and unlabeled and labeled corticosterone. Intra- and interassay coefficients of variation were less than 5 and $10 \%$ respectively. ACTH was determined by RIA according to the manufacturer's specification.

\section{Statistical analysis}

All data were expressed as means \pm S.E.M. Data were analyzed by two-way ANOVA with post-hoc comparison using Newman-Keuls test. Data on body weights and on the effect of obesity on the adrenal response to restraint stress and to ACTH in vitro were analyzed using Student's t-test. Differences were considered statistically significant when $P<0.05$.

\section{Results}

\section{Influence of agouti genotype on plasma ACTH and corticosterone levels in control and restrained mice}

Restraint stress significantly increased plasma ACTH concentrations in both $A^{y / a}$ - and a/a-mice (ANOVA, $P<0.001$ ), but agouti genotype had no effect on resting and stress-induced plasma ACTH levels (Fig. 1A).

There were no genotype differences in corticosterone plasma levels in control groups (Fig. 1B). Restraint stress significantly increased plasma corticosterone concentrations in both $A^{y / a}$ - and $a / a$-mice (ANOVA, $P<0.001)$, but the increase was greater in $A^{y} / a-$ mice (ANOVA, interaction genotype $\times$ treatment, $P<0.004)$. Therefore, stress-induced corticosterone levels in $A^{y} / a$-mice were 4 -fold higher than in $a / a$ mice (ANOVA, post-hoc comparison, Newman-Keuls post-hoc test, $P<0.001)$.

\section{Influence of agouti genotype on basal and ACTH-induced corticosterone release in isolated adrenal cells in vitro}

There were no genotype differences in corticosterone production without ACTH (Fig. 2). Administration of ACTH $\left(10^{-13}-10^{-10} \mathrm{M}\right)$ markedly increased the corticosterone release in adrenal cells of both $A^{y} / a$ - and
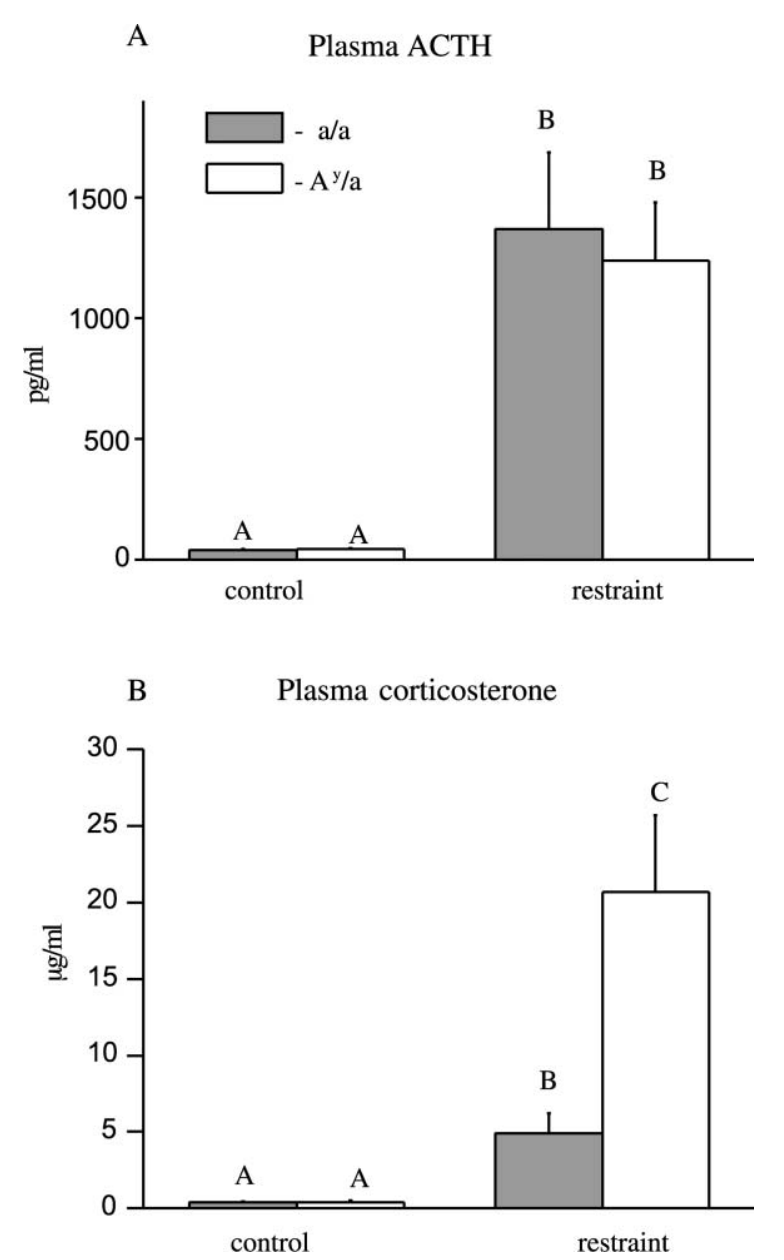

Figure 1 Plasma ACTH (A) and corticosterone (B) levels in control and restrained $A^{y} / a$ - and a/a-mice. Three-month-old $A^{y / a-}$ and $a / a-m i c e$ were subdivided into control and restraint groups (8-9 mice/group). Restraint mice were killed immediately after 15 min of restraint; control mice were killed within 2 min of disturbance. ACTH and corticosterone concentrations were measured in plasma. Data are means \pm S.E.M. Values that do not share a common letter are significantly different at $P<0.05$ (ANOVA, post-hoc Newman-Keuls test).

a/a-mice (ANOVA, $P<0.001$ ). $A^{y / a-m i c e ~ s h o w e d ~ a ~}$ greater increase of corticosterone release following incubation with ACTH compared with a/a-mice (ANOVA, $P<0.001$ ). The maximal corticosterone production in $A^{y} / a$-mice, induced by an ACTH dose of $10^{-11} \mathrm{M}$, was 2 -fold higher than that in a/a-mice.

\section{Agouti-genotype action on HPA sensitivity to dexamethasone}

Three hours after the administration of dexamethasone (DEX; $0.02 \mu \mathrm{g} / \mathrm{g}$ body weight), corticosterone output was strongly inhibited in unrestrained animals of both genotypes $\left(A^{y} / a\right.$-mice, $\quad P<0.01 ; a / a$-mice, $P<0.001$; ANOVA, post-hoc comparison, NewmanKeuls test) (Fig. 3). Restraint stress significantly 


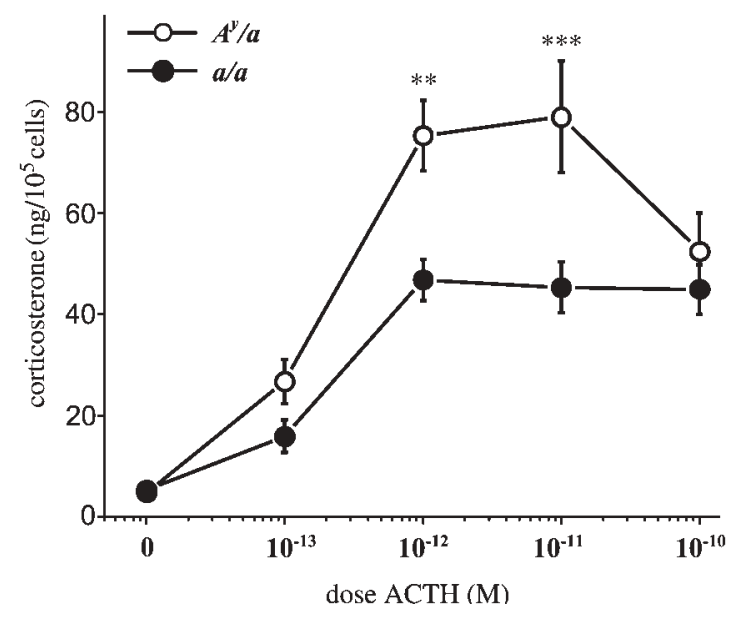

Figure 2 Effect of ACTH on the release of corticosterone from isolated adrenal cells in $A^{y} / a$ - and a/a-mice. Adrenal cells were incubated for $2 \mathrm{~h}$ in the absence or presence of various ACTH doses. Each symbol represents the mean corticosterone value from three experiments. In each experiment corticosterone production was measured in four aliquots of cell suspension obtained from five mice. Data are means \pm S.E.M. ${ }^{*} P<0.01$ and $\star \star \star P<0.001$ in $A^{y / a-m i c e ~ v s ~ a / a-m i c e ~(A N O V A, ~ p o s t-h o c ~}$ Newman-Keuls test).

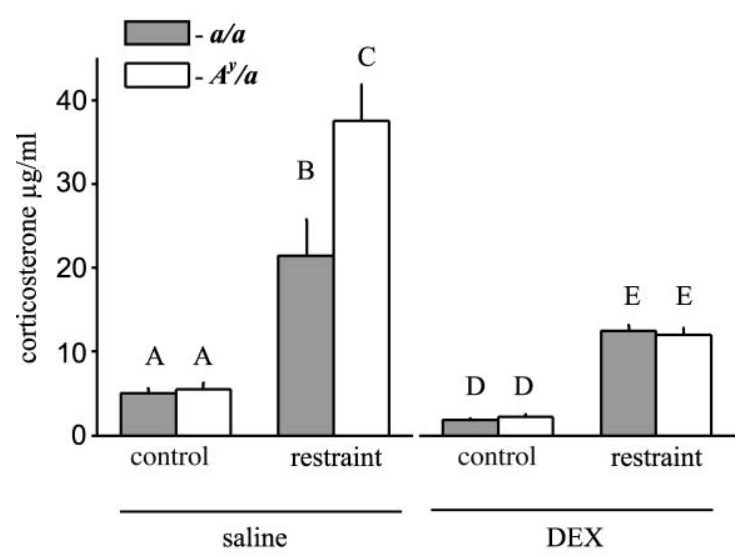

Figure 3 Suppression of restraint-induced plasma corticosterone levels in $A^{y / a-}$ and a/a-mice by dexamethasone. $A^{y / a-}$ and a/amice (12-13 mice/group) were injected i.p. with saline or with dexamethasone $(0.02 \mu \mathrm{g} / \mathrm{g}$ body weight) $3 \mathrm{~h}$ prior to $15-\mathrm{min}$ restraint stress. Corticosterone concentrations were measured in samples of blood collected, by tail nick, before and immediately after restraint stress. Data are means \pm S.E.M. Values of corticosterone that do not share a common letter are significantly different at $P<0.05$ (ANOVA, post-hoc Newman-Keuls test).

increased plasma corticosterone concentrations in saline-treated groups $(P<0.001$ in both genotypes; ANOVA, post-hoc comparison, Newman-Keuls test). The stress-induced corticosterone level in saline-treated $A^{y / a-m i c e}$ exceeded that for $a / a$-mice by 3 -fold $(P<0.05$; ANOVA, post-hoc comparison, NewmanKeuls post-hoc test), confirming data presented in Fig. 1A. Dexamethasone administration decreased the stress-induced levels of corticosterone in mice of both genotypes $\left(A^{y} / a\right.$-mice, $P<0.001$; $a / a$-mice, $P<0.05$; ANOVA, post-hoc comparison, Newman-Keuls posthoc test). There was a significantly greater inhibition of stress-induced corticosterone levels in $A^{y} / a$ mice than in a/a-mice (ANOVA, interaction genotype $X$ restriction $\times$ DEX; $P=0.007)$. As a result, in the DEX-treated group stress-induced corticosterone levels were similar in $A^{y / a}$ - and $a / a$-mice. Thus $A^{y / a}$ mice exhibited greater sensitivity to the suppressive effect of dexamethasone on stress-induced adrenocortical activity.

\section{Adrenal responses to restraint stress and to ACTH (in vitro) in obese/non-obese $A^{y} / a-m i c e$ and in a/a-mice}

The HPA response to restraint stress (Fig. 4A) and the adrenal cell response to exogenous ACTH (Fig. 4B) in $A^{y} / a$-mice were not associated with obesity, they were dependent only on agouti genotype. Stress-induced corticosterone levels were equal in non-obese and obese $A^{y} / a$-mice and were higher than those in $a / a$ mice $(P<0.001, t$-test for both cases $)$. ACTH-induced corticosterone production in vitro in non-obese and obese $A^{y / a-m i c e ~ w a s ~ e q u a l ~ a n d ~ w a s ~ m u c h ~ g r e a t e r ~}$ than in $a / a$-mice $(P<0.05$ for all ACTH doses).

\section{Discussion}

The present data demonstrate that under resting conditions there were no differences in the HPA axes of lethal yellow obese $A^{y} / a$-mice, with ectopic overexpression of AP, and black $a / a$-mice. Basal plasma concentrations of ACTH and corticosterone; basal corticosterone production in vitro; and feedback inhibition of resting corticosterone levels were similar in $A^{y / a-}$ and $a / a$-mice. Other authors $(9,10)$ have also found no differences in resting plasma corticosterone level between agouti genotypes. Overexpression of AP only affected the HPA axis in stressful conditions. Corticosterone responses to restraint stress in $A^{y} / a$-mice were higher than in $a / a$-mice whether they were obese or non-obese. Enhanced adrenal responses to restraint stress in $A^{y / a}$-mice were associated only with AP overexpression.

Increased corticosterone responses to restraint stress in $A^{y} / a$-mice were demonstrated in three experiments (Figs 1A, 3 and 4). Absolute values of corticosterone levels in all animals were higher in the last two experiments than in the first one. This difference may be explained by the blood-sampling method used. In the first experiment, blood was collected by decapitation while in the other experiments it was collected by tail nick. It is possible that the 2 min of tail nicking resulted in additional stress, which enhanced corticosterone blood levels under resting and stressful conditions. 


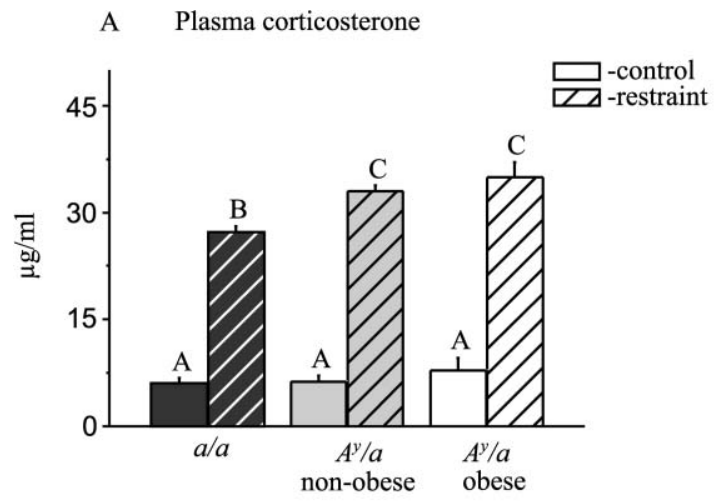

B Corticosterone production

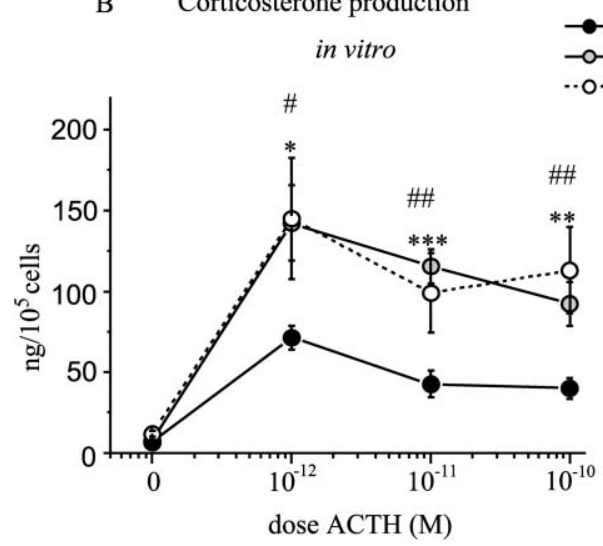

Figure 4 Adrenal responses to restraint stress $(A)$ and to $A C T H$ in vitro (B) in obese/non-obese $A^{y / a}$-mice and in a/a-mice. Threemonth-old $A^{y} / a$ males were subdivided into groups of obese and non-obese animals (body weights, correspondingly, $36.7 \pm 1.0$ and $26.0 \pm 0.8 \mathrm{~g}$ ). For comparison their a/a sibs were also studied (body weight $24.4 \pm 0.4 \mathrm{~g}$ ). Seven animals from each group were restrained. Blood was collected, by tail nick, before (control) and immediately after restraint stress (restraint). Data are means \pm S.E.M. Values of corticosterone that do not share a common superscript are significantly different at $P<0.05$ (Student's $t$-test)

Other animals (15 per group) were used for studying the effect of ACTH on the release of corticosterone from isolated adrenal cells. Adrenal cells were incubated for $2 \mathrm{~h}$ in the absence or presence of various ACTH doses. Each symbol represents the mean corticosterone value from three experiments. In each experiment, corticosterone production was measured in four aliquots of cell suspension obtained from five mice. Data are means \pm S.E.M. ${ }^{\star} P<0.05,{ }^{* *} P<0.01$ and ${ }^{* * *} P<0.001$, non-obese $A$ / $/ a$-mice vs a/a-mice; ${ }^{\#} P<0.05$ and ${ }^{\# \#} P<0.01$, obese $A^{y} / a$-mice vs a/amice (Student's $t$-test).

There are conflicting reports in the literature as to whether overexpression of AP does or does not enhance the stress response in mice. In transgenic mice, which also overexpress AP, plasma corticosterone after 30-min restraint was higher than in restrained wildtype mice (13). However, according to De Souza et al. (10) $A^{y} / a$-mice exposed to 1 -h restraint had the same amount of corticosterone as a/a-mice (10). Our data coincide with those reported by Harris et al. (13). An explanation for the discrepancy between our results and those reported by De Souza et al. (10) may be the differences in restraint-stress duration; we used a 15-min restraint while De Souza et al. used a 1-h restraint. The maximum responses of the stress effector systems are usually seen within the first 30 min after the beginning of immobilization stress (17). The longer the restraint time, the greater the dependence of corticosterone level on feedback inhibition. We found that the inhibitory effect of dexamethasone on restraint-induced corticosterone production was higher in $A^{y} / a$-mice than in $a / a$-mice. A more-rapid decrease in restraint-induced corticosterone concentrations in $A^{y} / a$-mice may be a possible reason for the equal plasma corticosterone concentrations after a 1-h restraint reported by De Souza et al. (10).

The enhanced corticosterone response in restrained $A^{y} / a$-mice compared with restrained a/a-mice was a result of increased adrenal reactivity to ACTH rather than reinforced ACTH production. We showed that plasma ACTH concentrations were similar in restrained $A^{y} / a$ - and $a / a$-mice, but $A^{y} / a$-mice had a stronger corticosterone release following incubation with ACTH in vitro as compared with a/a-mice. Until now, there has been no detailed work done to explain satisfactorily the high steroidogenic response to ACTH in $A^{y} / a$-mice. Therefore, only speculations can be made. The adrenal gland represents the second major AgRP-expressing tissue after the hypothalamus (18). This suggests that AgRP participates in adrenal function control. It has been shown that MSH - pro-opiomelanocortin (POMC)-derived peptide other than ACTH - can regulate adrenal steroidogenesis, inducing adrenal cell corticosterone secretion $(3,19)$ and enhancing the adrenal response to ACTH in vitro (19). Adrenal AgRP acting via MC3-R and MC4-R (which are expressed in the adrenal) may have an inhibitory paracrine role, blocking $\alpha$-MSH actions $(3,19)$. The agouti yellow mutation was shown to downregulate AgRP expression in the hypothalamus (18). If it is granted that the same down-regulation takes place in adrenal, the increased response to ACTH in $A^{y} / a$-mice may result from inhibition of AgRP expression in adrenals. The exact mechanisms of enhanced ACTH-induced steroidogenesis in $A^{y} / a$-mice remain to be investigated.

Genotype differences in stress-induced corticosterone levels, which mainly were associated with ACTHinduced corticosterone production, were eliminated by dexamethasone pre-treatment. Obviously, dexamethasone abolished genotype differences due to its effect on adrenal rather than central HPA links. Dexamethasone was shown to suppress the expression of some steroidogenic enzymes (20) and to enhance AgRP expression in the adrenal gland (3). Inhibition of stress-induced corticosterone levels by dexamethasone was markedly higher in $A^{y} / a$-mice compare with $a / a$ mice. The adrenals of $A^{y} / a$-mice were possibly more sensitive to dexamethasone, which resulted in equal stress-induced corticosterone responses in dexamethasone-pretreated $A^{y} / a$ - and a/a-mice. 
In summary, the results of the present study suggest that ectopic overexpression of AP increases the stress responsiveness of $A^{y} / a$-mice as measured by restraintinduced corticosterone release and adrenal response to ACTH stimulation in vitro, regardless of the obesity development. The inhibitory effect of dexamethasone on restraint-induced corticosterone levels was also stronger in $A^{y} / a$-mice than in $a / a$-mice. Thus, AP might have both stimulating and inhibiting influences on the HPA axis in mice.

\section{Acknowledgements}

This work was supported by research grants from the Russian Fund of Basic Researches (04-04-48760) and The State Program Supporting Leading Scientific Schools in Russia (1515.2003.4).

\section{References}

1 Griffon N, Mignon V, Facchinetti P, Diaz J, Schwartz JC \& Sokoloff P. Molecular cloning and characterization of the rat fifth melanocortin receptor. Biochemical and Biophysical Research Communications $19942001007-1014$.

2 Bicknell AK, Gladwell RT \& Lowry PJ. Agouti related protein in the rat adrenal cortex: implications for novel autocrine mechanisms modulating the actions of pro-opiomelanocortin peptides. Journal of Neuroendocrinology 200012 977-982.

3 Dhillo WS, Small SJ, Gardiner JV, Bewick GA, Whiteworth EJ, Jethwa PH, Seal LJ, Ghatei MA, Hinson JP \& Bloom SR. Agoutirelated protein has an inhibitory paracrine role in the rat adrenal gland. Biochemical and Biophysical Research Communications 2003 301 102-107.

4 Mountjoy KG, Robbins LS, Mortrud MT \& Cone RD. The cloning of a family of genes that encode the melanocortin receptors. Science $19922571248-1251$.

5 Wilson BD, Ollmann MM, Kang L, Stoffel M, Bell GI \& Barsh GS. Structure and function of ASP, the human homolog of the mouse agouti gene. Human Molecular Genetics 1995 4 223-230.

6 Lu DS, Willard D, Patel IR, Kadwell S, Overton L, Kost T, Luther M, Chen W, Woychik RP, Wilkison WO et al. Agouti protein is an antagonist of the melanocyte-stimulating-hormone receptor. Nature 1994371 799-802.

7 Yang YK, Ollmann MM, Wilson CD, Yamada T, Barsh GS \& Gantz I. Effects of recombinant Agouti-signaling protein on melanocortin action. Molecular Endocrinology $199711274-280$.
8 Bultman SJ, Michaud EJ \& Woychik RP. Molecular characterization of the mouse agouti locus. Cell 199271 1195-1204.

9 Wolff GL, Roberts DW \& Mountjoy KG. Physiological consequences of ectopic Agouti gene expression: the yellow obese mouse syndrome. Physiological Genomics 1999 1 151-163.

10 De Souza J, Butler AA \& Cone RD. Disproportionate inhibition of feeding in $A^{y}$ mice by certain stressors: a cautionary note. Neuroendocrinology 200072 126-132.

11 Karkaeva NR, Makarova EN, Yakovleva TV \& Bahzan NM. Effects of Agouti gene on function of pituitary-adrenal system in mice. Reports of Russian Academy of Sciences 2000373 88-91.

12 Karkaeva NR, Bahzan NM, Yakovleva TV \& Shevchenko AY. HPA function in mice with agouti protein overexpression. Russsian Physiological Journal $2003 \mathbf{8 9}$ 906-908.

13 Harris R, Zhou J, Shi M, Redmann S, Mynatt R \& Ryan DH. Overexpression of agouti protein and stress responsiveness in mice. Physiology and Behavior 200173 599-608.

14 Dhillo W, Small C, Seal L, Kim M, Stanley S, Murphy KG, Ghatei MA \& Bloom SR. The hypothalamic melanocortin system stimulates the hypothalamo-pituitary-adrenal axis in vitro and in vivo in male rats. Neuroendocrinology 200275 209-216.

15 Hustad CM, Perry WL, Siracusa LD, Rasberry C, Cobb L, Cattanach BM, Kovatch R, Copeland NG \& Jenkins NA. Molecular genetic characterization of six recessive viable alleles of the mouse agouti locus. Genetics 1995140 255-265.

16 Murphy BE. Some studies of the protein binding of steroids and their application to the routine micro and ultramicro measurement of various steroids in body fluids by competitive proteinbinding radioassay. Journal of Clinical Endocrinology and Metabolism 196727 973-990.

17 Pacak K \& Palkovits M. Stressor specificity of central neuroendocrine responses: implications for stress-related disorders. Endocrine Reviews $200122502-548$.

18 Ollmann MM, Wilson BD, Yang Y-K, Kerns JA, Chen Y, Gants I \& Barsh GS. Effects of recombinant agouti-signaling protein on melanocortin action. Science $1997 \mathbf{2 7 8} 135-137$.

19 Doghman M, Delagrange P, Blondet A, Berthelon M, Durand P, Naville D \& Begeot M. Agouti-related protein antagonizes glucocorticoid production induced through MC4-R activation in bovine adrenal cells: a possible autocrine control. Endocrinology $2004145541-547$.

20 Lee TC, Miller WL \& Auchus RJ. Medroxyprogesterone acetate and dexamethasone are competitive inhibitors of different human steroidogenic enzymes. Journal of Clinical Endocrinology and Metabolism $1999 \mathbf{8 4} 2104-2110$.

Received 2 December 2003

Accepted 3 May 2004 